\title{
Robotic Strategies to Assist Pilots in Landing and Takeoff of Helicopters on Ships and Offshore
}

\author{
Alexandre Campos, Jacqueline Quintero, Roque Saltarén, \\ Manuel Ferre and Rafael Aracil \\ Universidad Politécnica de Madrid \\ Spain
}

\section{Introduction}

A large number of maritime structures used for commercial, exploration and military purposes are equipped with a helicopter landing deck or winching area, respectively. Offshore flight operations are a highly complex and specialized process. It requires high levels of training, competence and skill to plan a flight, land and takeoff from an offshore installation even in good weather flying conditions. These operations can be seriously degraded by environmental effects that may be present around installations, vessels and their helidecks. The effects of wind turbulence from topsides structures or hot gases cause difficult landings and temporary loss of aircraft control by the pilot. Hot exhaust plumes from gas turbines on an installation can affect helicopter performance. The power output of the turbine engines on a helicopter is reduced as the air temperature at the intake increases. Rapid temperature changes can also induce engine surge and even compressor stall or flameout. The low cloud at helideck and other weather conditions affect visibility. The wind and wave induced dynamic motions on helidecks, on floating installations and vessels which represent a potential hazard to helicopter operations.

Therefore, development of new equipment and technologies are required in order to ease helicopter crew with the execution of flight operation. Aiming at assists pilots in these flight operations, we propose a new approach using an active helideck. Active-helideck based on Stewart-Gough platform is designed, developed, computational simulated and tested as a helicopter floating helideck. The objective of this testbed is to show the advantages of helicopters that use an active helideck upon landing on and taking off from ships or from offshore structures. Active-helideck compensates simulated movements of a ship at sea. The main goal of this study is to maintain the robot's end effector (helideck) in a quasi-static position in accordance to an absolute inertial frame. Compensation is carried out through the coordinate action of its six prismatic actuators in function of an inertial measurement unit. Moreover, the simulation of the sea movement is done by a parallel robot called ship platform with three degrees of freedom. A Computed Aided Engineering (CAE) system is used for modeling, simulation and analysis before construction testbed. The ship platform is 
built with a vertical oscillation along the $\mathrm{z}$ axis, $i$. e. heave, and rotates on remaining axes, $i$. $e$. roll and pitch. Active helideck is able to compensate simulated movements by considering the ship as an inertial frame as observed in the experiment.

Firstly, this chapter presents the different strategies used for assist crew in flight operation. Next, the testbed is described. Follow, kinematics model and control strategy for the testbed are explained. Then, it includes part of the results obtained through the simulation of testbed. It is then followed by the experimental procedure and results. Finally, conclusions are pointed out.

\section{Assistance strategies}

In order to assist crew in difficult maneuvers or tasks different strategies have been implemented. The wind based problems are identified through a wind-tunnel model study using flow visualization. The results determine appropriate position of the helideck, obstructions or exhausts, considered in design phase. Additionally, the designed helideck position should minimize its motion. Problem analysis result in operating limits being imposed by the helicopter operators.

Mathematical models for ship movements are formulated (Fossen, 2002), (Matusiak, 2002). Reliable information on weather and helideck motions needs to be provided at the flight aiming at outset maximum opportunity to be completed safely and efficiently or abort flight operations. Wave measurement (using pressure sensors, horizontal radars, vertically operating distance or velocity meter) and analysis with fast communication systems have been developed (Pajala, 2002). Moreover, by means of a satellite (e.g. ERS-1 European Remote-Sensing Satellite-1), wind and wave fields, sea-surface temperature, ocean tides, iceberg monitoring, oil and pollution detection can be determined. Satellite measurements combined with wave model gives real time wave information for sea operation (He \& Zinping, 1997), (Pajala, 2002). Furthermore, an aircraft/ship dynamic interface analysis simulation software package has been developed in order to analyze dynamic interface that exists between ships and embarked aircraft. It has been extensively validated and applied (Linn \& Langlois, 2006), (Langlois \& LaRosa, 2003). Aircraft performance data is scheduled in the flight manual and/or the operations manual which enables flight crew to accommodate the varying ambient conditions and operate in such a way that the helicopter has sufficient space and engine performance to approach land and take off from helidecks in securely.

Computer simulations are some approaches carried out for studying this case. Oh et al. design an autopilot for autonomous helicopter landing on a rocking ship through a tether in helideck (target) tracking (Oh et al., 2005), (Oh et al., 2006). In this case, a controller is considered to ensure the landing of a helicopter on a ship based on measurement of angle between the helicopter/ship and the cable. The tether permits divide the problem of landing in two control problems, position control and attitude-altitude control. In the first, when the helicopter is far the destination, the rotation reference signals are used to control the translation of the helicopter. In the second, due to coupling of the translation of the helicopter to the rotation through the tether, the translation reference rates are created to achieve a desired behavior attitude and altitude.

Dalamagkidis et al. design a gimbaled landing platform on an unmanned ground vehicle (UGV) (Figure 1). Instead of a ship, an UGV is used in order to transport miniature vertical takeoff and landing (VTOL) (Dalamagkidis et al., 2006). A two-axes gimbaled is used for 
ensuring a horizontal landing and free from vibrations platform for the VTOL, even during the movement of the UGV. The inertial measure unit (IMU) of UGV provides the heading and elevation of the platform. Then the platform is first rotated around the heading axis until the elevation axis is horizontal and after heading has been changed, the platform will be rotated around its new elevation vector, until the heading vector is vertical; the platform assumes a horizontal pose.

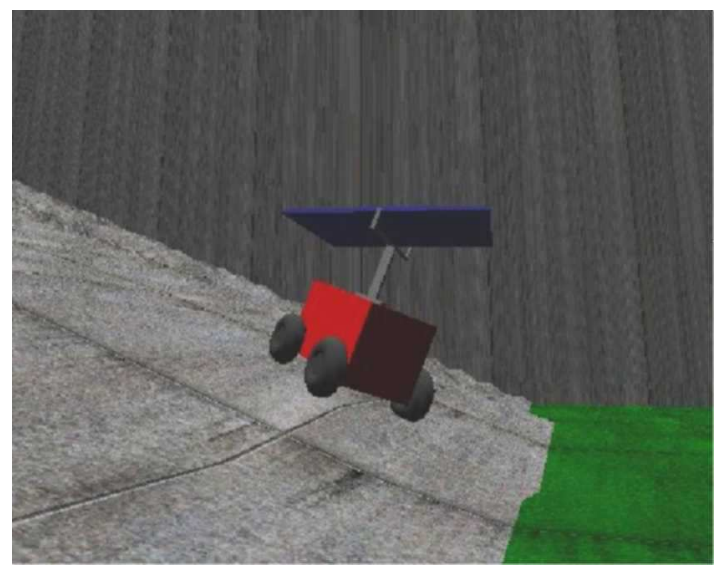

Fig. 1. 3D representation of the landing platform installed on UGV top (Dalamagkidis et al., 2006)

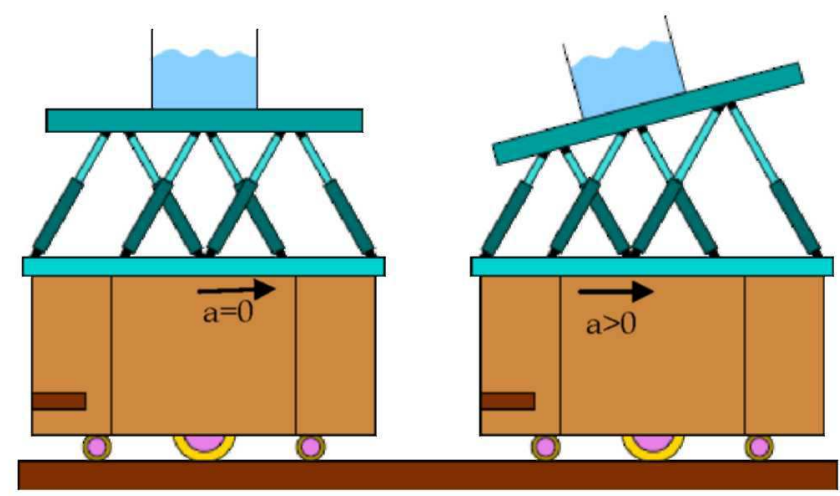

Fig. 2. The Stewart Platform is installed on MORTIMER (Graf \& Dillmann, 1997)

Before Dalamagkidis a similar configuration was used, but the platform mounted on the vehicle is used to aceleration compensation of it. Graf and Dillmann used a Stewart platform installed on the mobile robot so that abrupt vehicle movements and accelerations affect the object in a smooth way in $\mathrm{x}$ - and y-direction. The Stewart platform is moved so that the gravity create a contrarily directed acceleration (Graf \& Dillmann, 1997), (Graf \& Dillmann, 1999) as is show in the Fig 2. 
The controller of the stewart platform is connected directly to the controller of the mobile system to get the latest acceleration values all the time. The acceleration vector of the robot is inverted and transformed into the coordinate system of the platform. A double integration is realized to get position and orientation data for the platform. The inverse kinematics deliver the length of the legs.

With similar objectives Dan and et al. mounted at the top of the mobile base is the planar 3RRR manipulator which serves as compensation device (Decker et al., 2001), (Dang \& Ebert-Uphoff, 2004). The compensation platform moves in three degrees of freedom (DOFs): translation and rotation in the vertical plane (see Figure 3). They decided for a three degreesof-freedom motion planning algorithm, based on a combination of flexible local optimization scheme based on feedback algorithms (FMPA) and a so called Pendulum Algorithm (3DOF-FMPA). The pendulum algorithm emulates the response of a virtual pendulum when subjected to linear accelerations applied at its pivot point. The object is attached to the virtual pendulum. This pendulum approach is motivated by the fact that the free swinging motion of a pendulum automatically minimizes the lateral force acting on the object. For this application, the linear acceleration of the mobile robot is mapped to the linear acceleration of the pendulum's pivot point. The resulting linear motion of the pendulum's tray is mapped to the linear acceleration of the parallel platform.

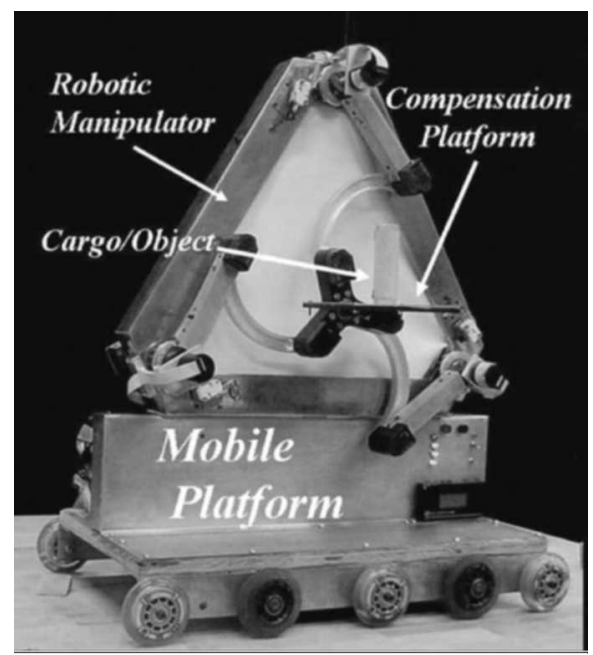

Fig. 3. Testbed consisting of mobile base with acceleration compensation platform acting in vertical plane (Dang \& Ebert-Uphoff, 2004)

At present chapter, a new approach using an active helideck is intorduced. Its aim is to compensate possible movements of a landing platform caused by wind and/or waves. A 6dof parallel robot has been designed, simulated and built (see Figure 4). Its objective is to test active helideck on a moving structure. A ship at sea movement simulator named ship platform has been designed and built. The more important offshore structure movements: roll, pitch and heave (Fossen, 2002), are considered; therefore a 3 dof parallel platform (Cheng, 1994), two of rotation and one of movement along the vertical axis have been used as a ship platform. 


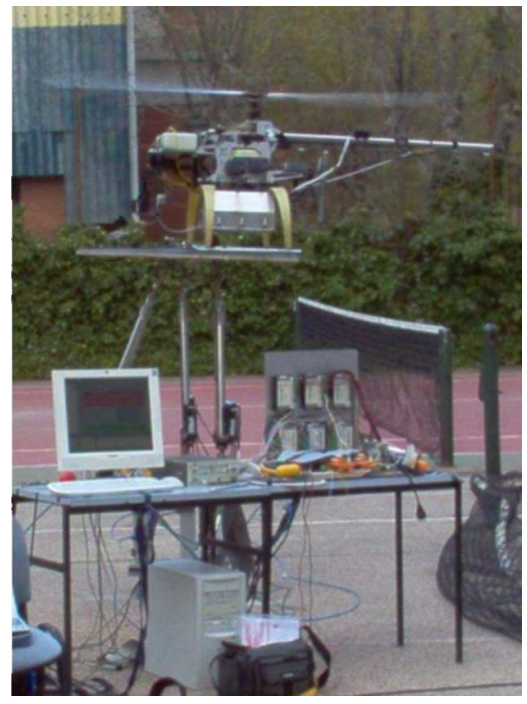

Fig. 4. Testbed: active helideck (AH) and ship platform (SP)

\section{Testbed Description}

In order to compensate helideck movement with the wind and wave effects on the ship's hull, as well as simulating this movement in the testbed, some dimension considerations have taken into account. The position amplitude is $0.1 \mathrm{~m}$, orientation amplitude is $6^{\circ}$ and wave period is $10 \mathrm{~s}$. Orientation angle and the wave period were taken from RMS values of general operability limiting criteria for ships (Nordforsk, 1987). On the other hand, a big ship has been considered in order not to take into account scaling factors in terms of size and mass/inertia properties or transients due to helicopter landing/taking off for this testbed.

The testbed in this study is based on parallel robot architecture, i.e. a closed kinematics chain. A 6 dof Stewart-Gough platform is selected for the active helideck (Stewart, 1966), (Merlet, 2000) as shown in Figure 5.

Stewart Platforms are mainly used for flight or driving simulators (Baret, 1978) and for machine tools (Pierrot et al., 2001), (Thomas et al., 2002). The advantages of Stewart Platforms are the excellent weight and payload capability ratio and precise positioning (Merlet, 2000). A Stewart platform is commonly used in obtaining acceleration, but it can also generate an anti acceleration if the base platform is moving (Graf \& Dilmann, 1997); application of Stewart platforms compensate acceleration of a moving robot. However, only vibrations of relatively minimal amplitude are considered (Graf \& Dilmann, 1997), (Geng \& Haynes, 1993), (Cobb et al., 1999), (Vaillon et al., 1999). A greater amplitude is considered in vibration control simulation of a Stewart-Gough platform on flexible suspension (Cheng et al., 2003), where the platform compensates the movements of a radio telescope mounted at a suspending structure. In such case, expected wind-induced vibration can be as high as $0.5 \mathrm{~m}$ in position and $3^{\circ}$ in orientation. In this given case, the reaction force caused by the motion 
of the stabilized platform will lead to perturbation on the base platform as the base platform is not fixed on the ground. It will then induce vibration on the whole system.

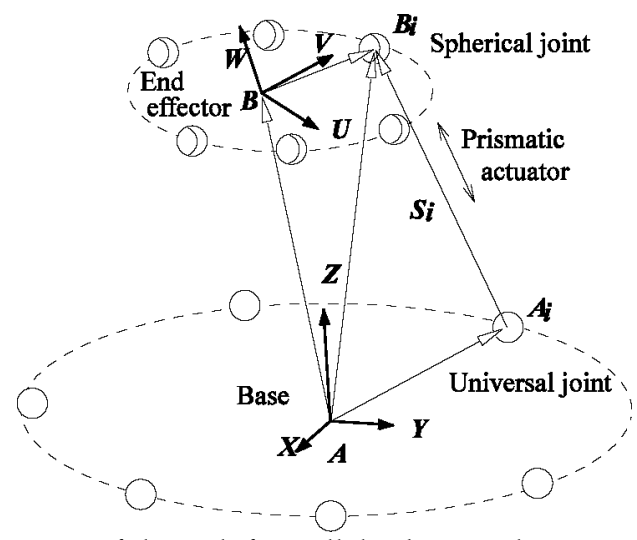

Fig. 5. Schematic architecture of the 6-dof parallel robot used as active helideck

Aiming at simulating the ship movement, the closed kinematic chain used is the 3-dof parallel manipulator shown in Figure 6.

In this chapter, the proposed alternative is a testbed compounded by two main parts, see Figure 4, the ship platform from now on named SP, i. e. a ship at sea movement simulator, and the active helideck from now on named $\mathbf{A H}$, i. e. a Stewart-Gough platform.

\subsection{Active Helideck}

The active Helideck (AH) is a Stewart-Gough platform 6-UPS (Universal, Prismatic, Spherical) whose end effector (helideck) is connected to the base, i. e. SP end effector, through six prismatic electrical actuators. Prismatic actuators are connected to the end effector by spherical joints and to the base by universal joints. Ball screws actuated by electric brush-less motors have been used considering prismatic movement.

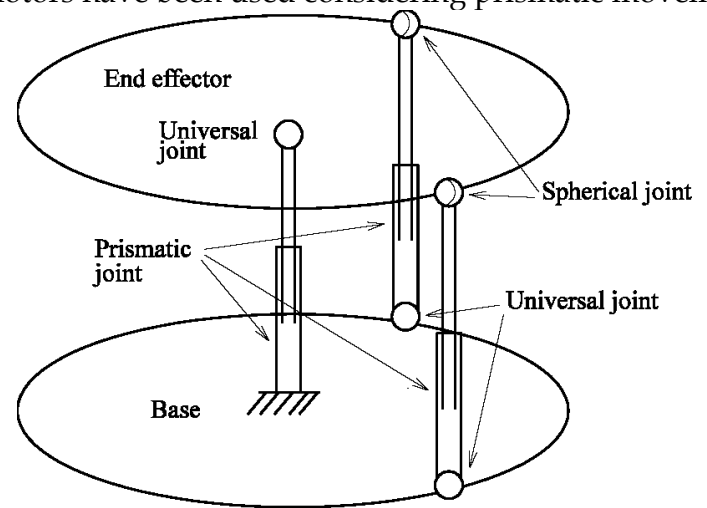

Fig. 6. Schematic architecture of the 3-dof parallel robot used as ship movement simulator 


\subsection{Ship Platform}

The SP requires that its platform end effector (base of $\mathbf{A H}$ ) moves along vertical axis $(Z)$, taking into account ship movement heave, rotation around axes $X$ and $Y$ with respect to its base, and also roll and pitch from ship movements. Therefore, a 3dof parallel platform is constructed which consists of four pneumatic prismatic actuators respectively controlled by proportional valves:

- Two pneumatic cylinders fixed to the base that are connected by a universal joint to the end effector (ship hull). These cylinders move simultaneously in order to control height, $i$. e. heave of the SP end effector. These two cylinders are cinematically considered as one central cylinder.

- Two pneumatic cylinders provide the rotational movements, i. e. roll and pitch; these cylinders, called external cylinders, are connected by universal joints to the base and by spherical joints to the end effector.

Therefore, AH compensates the movement of the SP in order to maintain the deck, placed on its end effector, in a quasi-static position. The constructed testbed is shown in Figure 7. Two sensors are installed on the testbed in order to obtain the information from the environment which allow actuating the AH conveniently. An inertial measurement unit (IMU) is located at the SP end effector in order to get its instantaneous orientation, through Euler parameters. An ultrasonic length sensor is used to quantify SP height that has to be compensated in order to keep the helideck in a quasi-static height.
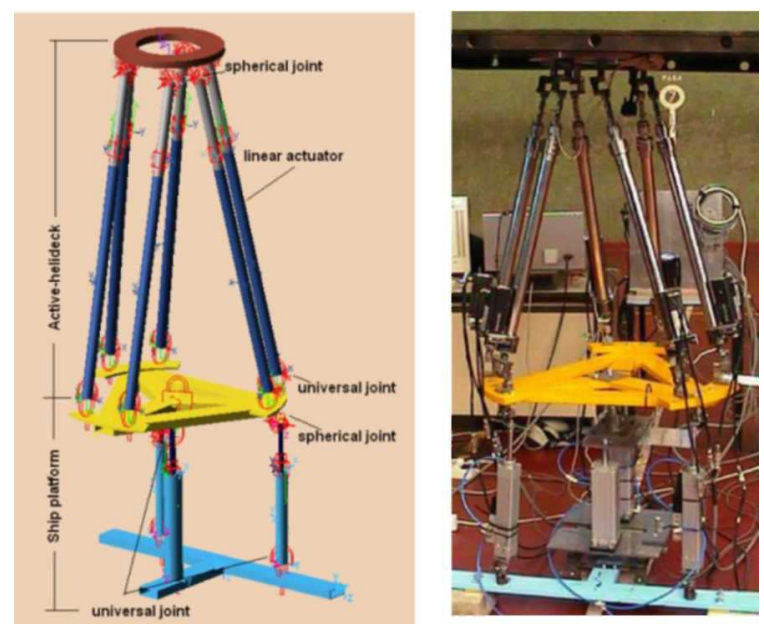

Fig. 7. Testbed for computational simulation and for real testing

\section{Kinematic model}

Using the concepts of the parallel robot inverse kinematics, control signals can be obtained in order to determine $\mathrm{AH}$ coordinate movements according SP behavior. This inverse kinematics calculates the limb lengths, which is reached through the active prismatic joints (see Figure 5), given the SP location (position and orientation). 


\subsection{Mathematical Tools}

Two Cartesian coordinate systems are attached to base and moving platform in order to calculate parallel robot inverse kinematics. Frames $A(X, Y, Z)$ and $B(U, V, W)$ respectively as shown in Figure 5.

Each joint location in the base is described by the position vector $A_{i}$ in the coordinate frames A. Similarly, each joint location in the end effector is described by the position vector $B_{j}$ in the coordinate frame $B$. Therefore, the $i$-th limb length is the magnitude of the vector directed from $A_{i}$ to $\mathrm{B}_{\mathrm{i}}$, i. e. $\mathrm{S}_{\mathrm{i}}$ :

$$
d_{i}=\left|S_{i}\right|=B_{i}-A_{i}
$$

In order to carry out the vectorial subtraction of (1), the vectors must be expressed in the same reference frame. A point $p$ expressed in reference frame $B$ may be expressed in reference frame $A$, using the matrix of homogeneous transformation (Tsai, 1999):

$$
A_{T_{B}}=\left[\begin{array}{cc}
A_{R_{B(3 x 3)}} & A_{q(3 x 1)} \\
\gamma_{(1 \times 3)} & \rho_{(1 \times 1)}
\end{array}\right]
$$

Then using the matrix of homogeneous transformation, the position in the new reference frame is obtained by:

$$
\begin{gathered}
A_{P}={ }^{A} T_{B}{ }^{B} p \\
{ }^{A} p={ }^{A} q+{ }^{A} R_{B}{ }^{B} p
\end{gathered}
$$

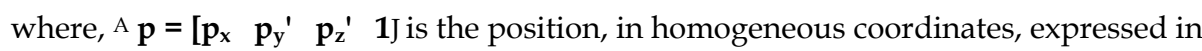
reference frame $A$ and ${ }^{\mathbf{B}} \mathbf{p}=\left[\mathbf{p}_{\mathbf{u}}{ }^{\prime} \mathbf{p}_{\mathbf{v}} \mathbf{p}_{\mathbf{w}}{ }^{\prime} \mathbf{1}^{\wedge}\right.$ is the position in homogeneous coordinates as expressed in reference frame $B$.

\subsection{Testbed kinematic model}

Three reference frames are selected in the testbed: global reference frame $G$, located at the SP base; reference frame $A$ located at the SP end effector (or AH base), and the reference frame $B$ located at $\mathbf{A H}$ end effector, see Figure 8. Initially these frames are oriented according the IMU axes as ruled by: $X$ axis yields along magnetic north direction and $Z$ axis aligns to gravitational force direction. The IMU is attached to the SP end effector. It is used to measure its orientation through the four Euler parameters $\left(e_{0}, e_{i}, e_{3}\right)$.

The coordinates of the universal joint axes that connect the prismatic actuators at $\mathbf{A H}$ end effector are determined in a Cartesian coordinates system relative to reference frame $B$. The points where the $\mathbf{A H}$ actuators are attached to their base $\left(A_{i}\right)$ are specified on reference frame $A$. Additionally, the points where the SP pneumatic cylinders are attached to the $\mathbf{A H}$ base $A_{i}$ are specified on reference frame $A$ too. Finally, the points $G_{i}$ where pneumatic cylinders are attached to SP base (ground) are specified on reference frame $G$, as shown in

Figure 8. 


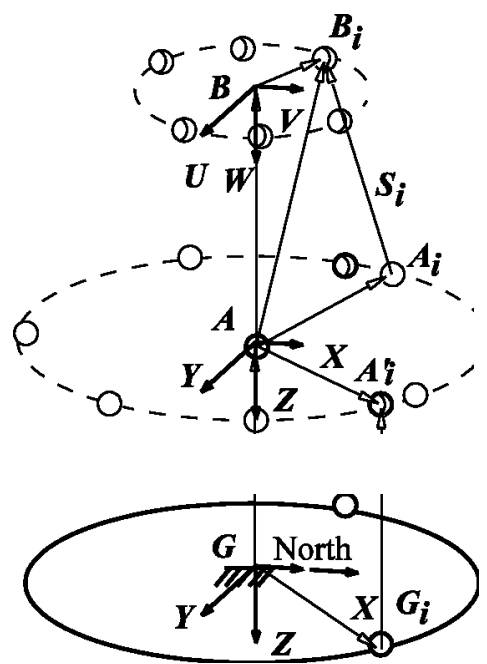

Fig. 8. Reference frames fixed at experimental platform

\section{Control strategy}

The objective of this control strategy is to determine SP and AH displacements; in such a way that SP represents the sea movements that have to be compensated by $\mathbf{A H}$ aiming at a quasi-static deck. A schematic diagram for the experimental platform is presented in Figure 9.

\subsection{Ship Platform Strategies of Movement}

Ship movements are described through sinusoidal displacements for the pistons. It is important to notice that the central cylinder determines the ship hull heave. The combination of central and external cylinders determines the ship hull pitch and roll. The displacement of the SP central cylinder is sinusoidal around a initial position and independent from the two external cylinders. This displacement causes the desired heave for the SP. External cylinders move follow a sinusoidal displacement too. The SP control loop movement is closed with the IMU attached in the SP end effector and with the ultrasonic length sensor which measures the SP end effector height. This loop for the SP movement is closed with the IMU attached in the SP end effector and with the ultrasonic length sensor which measures the SP end effector height.

The rotation matrix is obtained by using values provided by IMU, the reference frame A origin position is $[0,0, z]$ with respect to reference frame $G$, where $z$ is read by a ultrasonic sensor, and the origin position of the reference frame $\mathrm{B}, i$. e. the desired deck height, has to be well-known and it is indeed a variable to control. Through the inverse kinematics, effective displacements that must be reached to obtain the desired total displacement of the actuator are calculated in accordance to current position and orientation of the SP. The sinusoidal movements of the external actuators are out of phase in order to provide movement around $\mathrm{X}$ axis, i. e. pitch. The central piston is out of phase in order to obtain oscillations around the y axis, i. e. roll. 


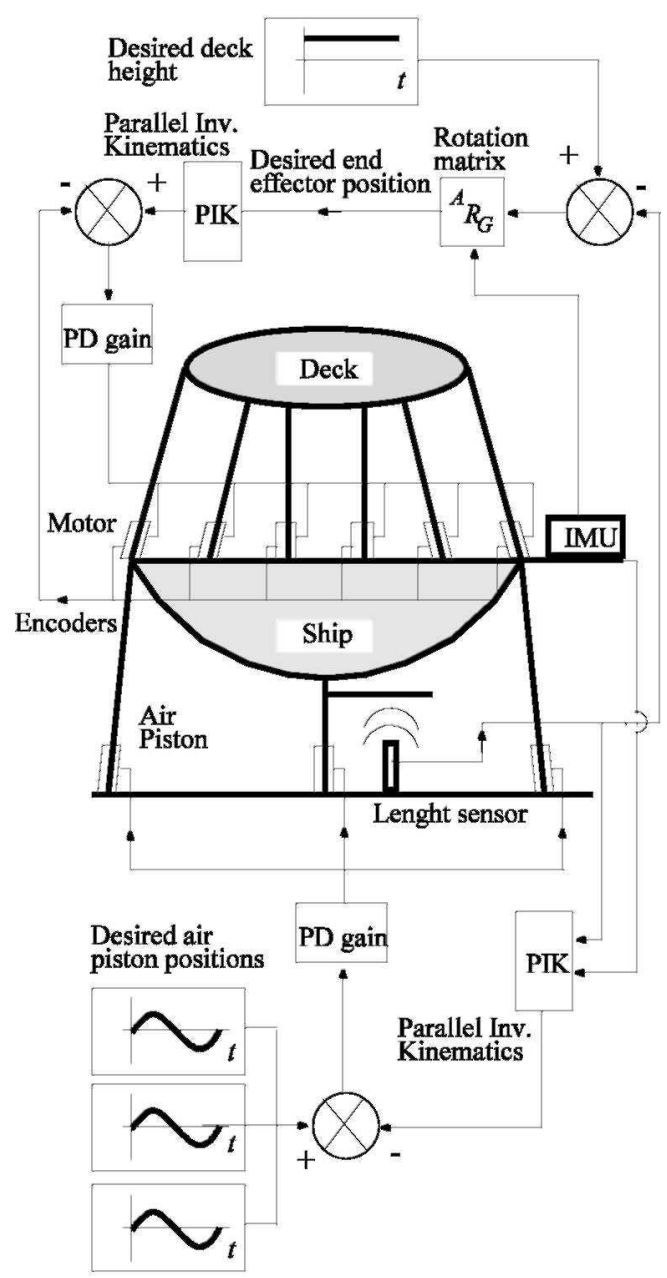

Fig. 9. Testbed schematic diagram

\subsection{Active Helideck Strategies of Movement}

The helideck end effector is required to remain in a constant position and orientation with respect to the inertial frame G. Aiming at such, it is then necessary to calculate the AH actuator displacements according to the instantaneous SP position and orientation. Nevertheless, applying the equations of inverse kinematics, $\mathbf{A H}$ end effector position has to be determined with respect to the reference frame G. Using Eq. (2), transformation of coordinates are calculated:

$$
{ }^{A} p_{f}=\left[\begin{array}{ccc}
{ }^{A} R_{G} & { }^{A} R_{G} \\
{\left[\begin{array}{lll}
0 & 0 & 0
\end{array}\right]} & 1
\end{array}\right]
$$

where,

${ }^{G} p_{f}$ is the helideck end effector position with respect to inertial reference frame $G$. This value 
is maintained constant for any movement of inferior platform.

${ }^{A} p_{f}$ is the position of the frame $G$ with respect to frame $A$. This position is obtained by:

$$
{ }^{A} R_{G}={ }^{A} R_{G}\left(-{ }^{G} p_{A}\right)
$$

${ }_{A} R_{G}$ is the rotation matrix of frame $G$ respect to frame $A$. This it is obtained transposing the rotation matrix $\mathrm{GR}_{\mathrm{A}}$.

Finally, AH actuator lengths are calculated by using parallel inverse kinematics (IPK).

\subsection{Position Control}

Control stage is based on a dSPACE tm DS1103 card. DS1103 is a digital signal processor (DSP) on a PC platform where the controller can be easily programmed. The control law is introduced in C environment, then compiled and downloaded to DS1103 card using real time tools included in the Control desk package (dSpace, 2001). The controller card captures voltage signals from inertial measure unit, length sensor and motor encoders. It also calculates every three millisecond new control signal and feeds the motor amplifiers and the air piston proportional valves.

Control position for both platforms (i. e. SP and AH) is performed through proportional derivative PD controllers so as to assure stability even with errors in steady state. These PD gains for electric motors and for pneumatic proportional valves are tuned experimentally. It is important to consider that due compressive air properties, air pistons' behavior is different when moving up or moving down. Therefore, two different PD gains are set to each pneumatic piston.

\section{Computational simulation}

Prior to the implementation of the first active helideck prototype, a Computer Aided Engineering (CAE) system to simulate the testbed is used. The CAE system employed permits to build models of mechanical systems and to simulate the full-motion behavior of the models. A powerful numerical analysis automatically solves the equations of motion for kinematic, static and dynamic simulations, that lets animate and optimize these models. In this work, the computational simulation confirms kinematics of the robot, its workspace and predicts the behavior of the system before the proposed control algorithms. Primitive geometries of software are used to model the true prototype, as shown in Figure 7. Measures position and orientation of the $\mathbf{A H}$ base are used to simulate the sensors. A movement for each of the linear actuators is imposed according sea movement and the resulting SP motion effector is validated. According to the obtained measurements, the necessary displacement for each linear actuator of the helideck is estimated. Therefore, the AH prismatic joints, are actuated based on this estimation. Through this simulation, we verify that the required displacements for the AH prismatic joints fulfill the conditions to keep the helideck in a quasi-static position, using a PD control strategy.

Simplified models were also made to determine the height to which should be placed the AH end effector, in order to optimize the necessary forces on the actuators. The results of the simulations are summarized in Figure 10, where the maximum required force versus the desired (initial) height is plotted. For different heights, we examined the required forces in 
each actuator, for a full cycle of movement. The initial position of AH end effector is chosen (so that the maximum force required is minimal $1142 \mathrm{~mm}$ respect its base).

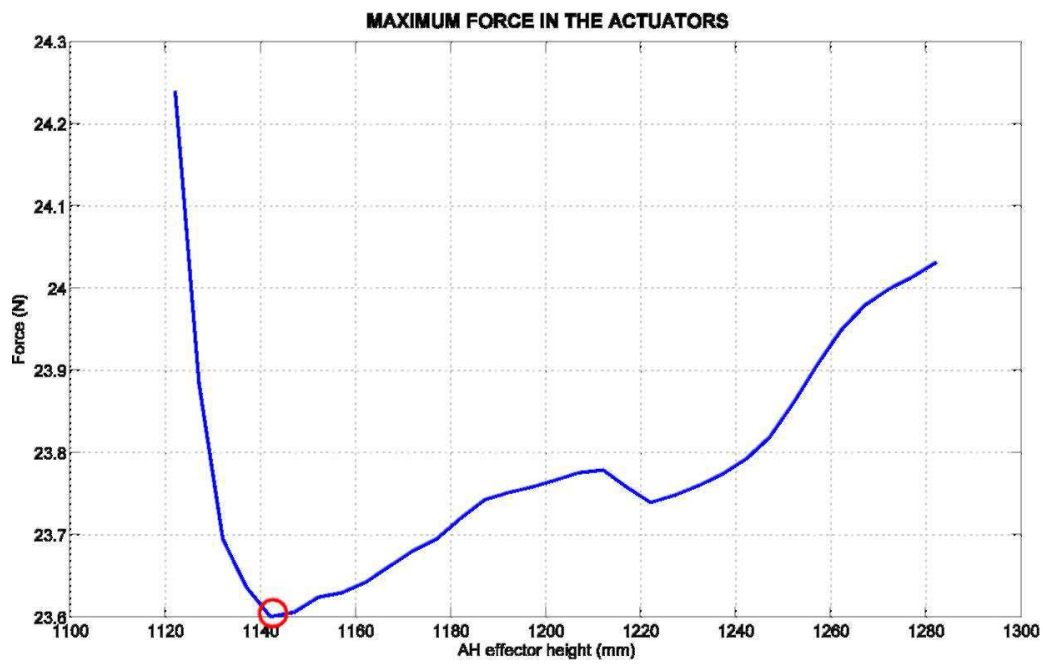

Fig. 10. Maximum force exerted on the linear actuators

\section{Experimental test}

Tests have been carried out on the experimental platform in the laboratory and then in field as have been shown in sequence of Figure 11. This test is required to verify that the helideck (AH end effector) remains quasi-static in spite of SP movements.

Initially, a trajectory planner is used for moving the helideck to a position that allows the actuator movements aiming at compensating the inferior platform movements at any moment. During this time the inferior platform pneumatic actuators are locked. Then, external pneumatic cylinders are driven in order to carry out SP to a horizontal position. At that moment AH control is activated to compensate the SP movement. Then, all the pneumatic cylinders are moved to the middle of their strokes and begin a sinusoidal movement. This movement causes a variation in inferior platform orientation and position, which is measured by the sensors. From the sensors information, the processor calculates the AH actuators' displacement needed to hold its fixed location with respect to the inertial frame. Using this information, the actuators are energized through the amplifiers. After that the helicopter approaches and lands on compensated helideck.

Finally, the position and orientation of helideck and inferior platform are compared in order to observe the compensation and the deck's desired behavior. 


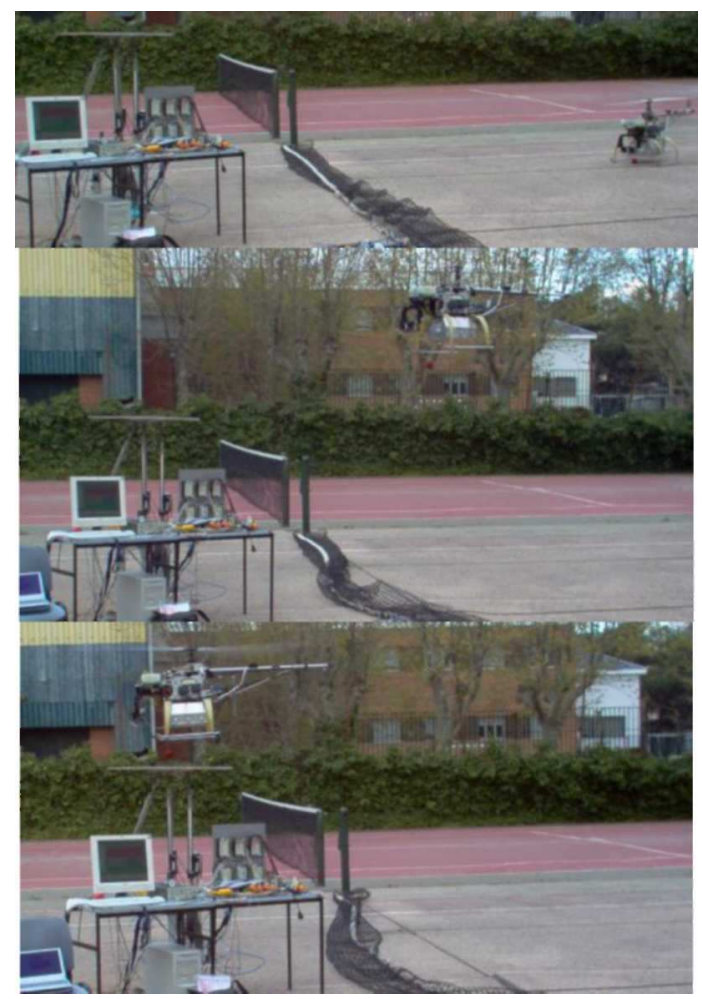

Fig. 11. Helicopter approaching and landing on Helideck

\subsection{Experimental Results}

From the experimental results, the position and orientation variation between helideck and inertial frame can be observed.

The orientation is described through Euler parameters $\left(e_{0}, e_{1}, e_{2}\right.$ and $\left.e_{3}\right)$, where $e_{0}$ is associated to the rotation angle around the axis whose $X, Y$ and $Z$ components are associated ej, $\mathrm{e}_{2}$, and $\mathrm{e}_{3}$.

From Figure 12, SP presents an angular oscillation around $X$ (roll) and $Y$ (pitch) axis representing the sea movement. Additionally, the helideck orientation remains quasi-static in relation to the inertial frame in spite of the orientation variation of its base, i. e. the SP. It is important to highlight that the desired reference Euler parameters, for a horizontal deck position, are $e_{1}=1$ and $e_{1}=e_{2}=e_{3}=0$.

In Figure 13 is shown the helideck displacement with respect to SP aiming at remaining quasi-static with respect to inertial frame as desired. $\mathbf{A H}$ has to compensate the vertical movements as well. Last plot of Figs. 13 shows the helideck behavior for a given wave input, represented by inferior platform vertical movement. It is worth mentioning that the noise in the signal is caused by the use of the ultrasonic length sensor. 

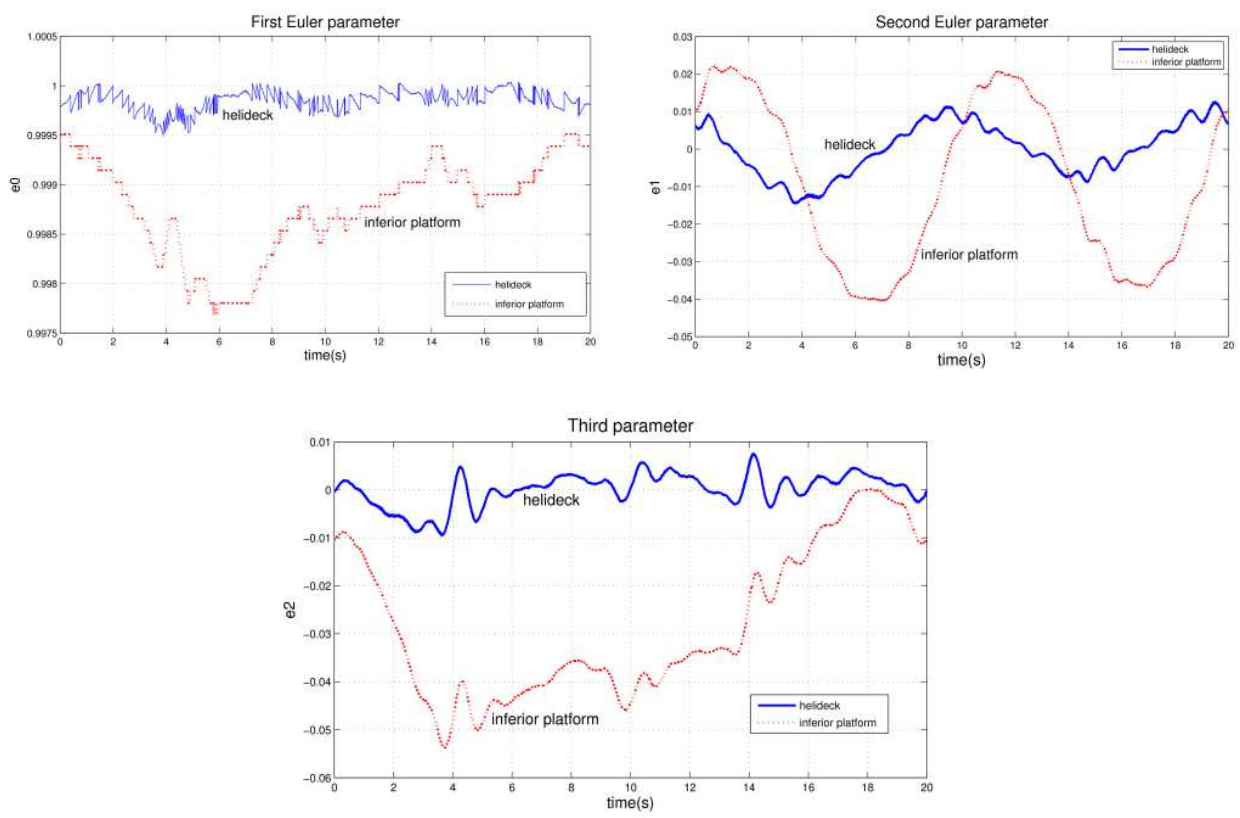

Fig. 12. Euler parameters $(e 0, e 1, e 2)$ for helideck and SP
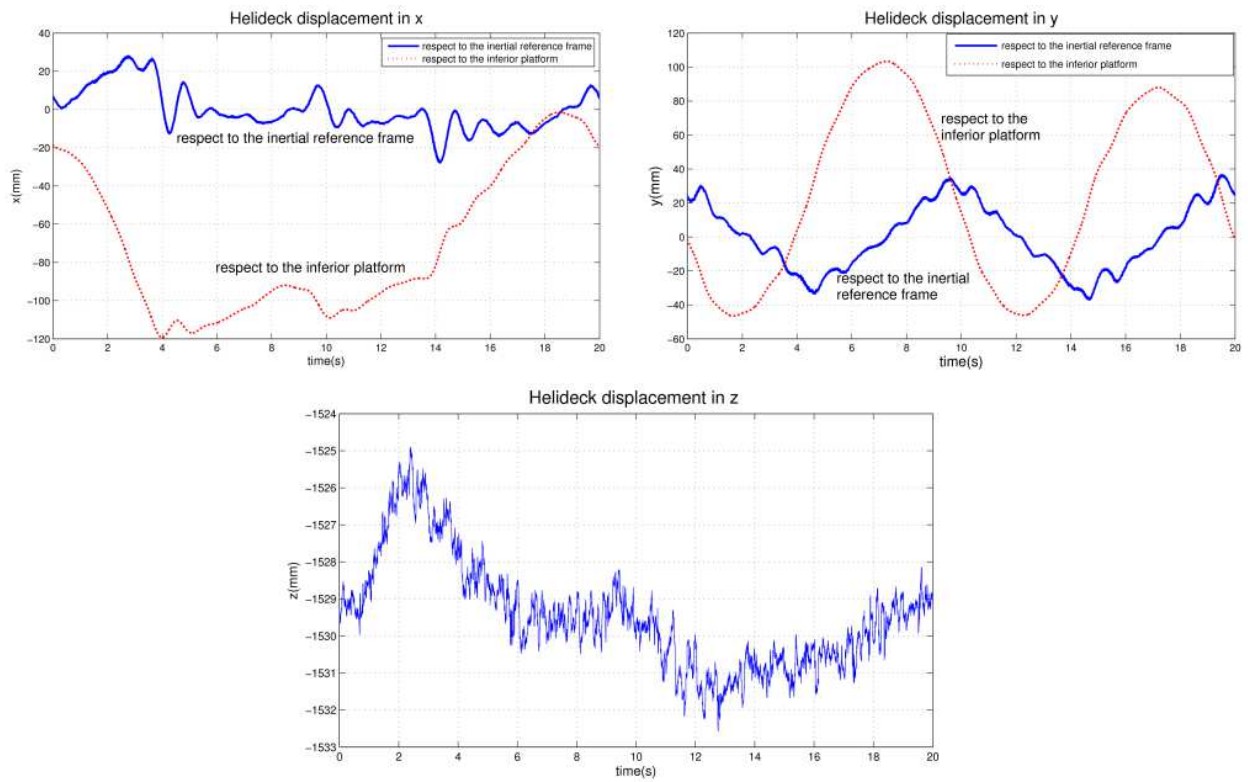

Fig. 13. X, Y, y Z position coordinates for helideck with respect to SP and to inertial frame 


\section{Conclusions and future works}

Several solution strategies have been proposed to assist helicopter pilots en offshore operations (landing and taking off). These strategies are in general based on measurement, mathematical models and computational simulation.

A testbed based on Stewart-Gough platform has been used, built and tested as helicopter deck. It was observed through computational simulation and experimental test that the active helideck is able to compensate the simulated movement provided by the sea to a ship or off-shore structure in order to ease helicopter landing and take-off maneuvers, considering a big enough ship with inertial frame properties.

For the testbed, a simulation analysis has determined the most suitable height of the $\mathbf{A H}$ end effector. This is next to the minimum height required to allow compensation of the movement.

The Stewart-Gough platform used in this study can still be improved with a larger base diameter so that the desired helideck angles and height could be attained. However, active helideck inertia due the ship platform motion could decrease.

A dimensional analysis for ship mass/inertia could be done in order to closely simulate a real ship's behavior.

\section{References}

Baret, M. (1978). Six Degrees of Freedom Large Motion System for Flight Simulators, Piloted Aircraft Environment Simulation Techniques, Proceedings of AGARD Conference No. 249, Piloted Aircraft Environment Simulation Techniques, pp. 22-1/22-7, Bruxelles.

Cheng, H. (1994). Real-Time Manipulation of a Hybrid Serial-and-Parallel Driven Redundant Industrial Manipulator. J. of Dynamic Systems Measurement and ControlTransactions of the ASME, Vol. 116, No. 4, pp. 687-70.

Cheng, G.; Ren, Y. \& Dai, S. (2003). Vibration Control of Gough-Stewart Platform on Flexible Suspension. J. of Robotics and Automation, IEEE, Vol. 19, No. 3, pp. 489-493.

Cobb R.; Sullivan J.; Das A.; Davis L.; Hyde T.; Davis T.; Rahman Z. \& Spanos J. (1999). Vibration Isolation and Suppression System for Precision Payloads in Space. J. of Smart Materials and Structures, Vol. 8, No. 6, pp. 798-812.

Dalamagkidis, K.; Ioannou, S.; Valavanis, K. \& Stefanakos, E. (2006). A Mobile Landing Platform for Miniature Vertical Take-off and Landing Vehicles, Proceedings of the 14th Mediterranean Conference on Control and Automation - MED '06, IEEE, pp. 1-6 Barcelona.

Dang, A. X. \& Ebert-Uphoff, I. (2004). Active Acceleration Compensation for Transport Vehicles Carrying Delicate Objects. IEE Transactions on robotics, Vol. 20, No.1 5, Oct. 2004, pp. 830-839.

Decker, M. W.; Dang A. X. \& EbertUphoff Imme. Motion Planning for Active Acceleration Compensation. Proc. IEEE Int. Conf. Robotics and Automation, , pp. 1257-1264, Seoul, Korea, May 21-26, 2001.

dSpace GmbH (2001). DS1103 PPC Control Board Hardware Reference, Germany.

Ford, T.; Hardesty, M. \& Bobye, M. (2005). Helicopter Ship Board Landing System, Proceedings of the 18th International Technical Meeting of the Satellite Division, ION GNSS, pp. 979-988, Long Beach, CA. 
Fossen, T. (2002). Marine Control Systems: Guidance, Navigation and Control of Ships, Rigs and Underwater Vehicles, Marine Cybernetics AS, Trondheim, Norway.

Geng, Z. \& Haynes, L. (1993). 6-Degree-of-Freedom Active Vibration Isolation Using a Stewart Platform Mechanism. J. of Robotic Systems, Vol. 10, No. 5, pp. 725-744.

Graf, R. \& Dillmann, R. (1997). Active Acceleration Compensation Using a Stewart-Platform on a Mobile Robot, Proceedings of the 2nd Euromicro Workshop on Advanced Mobile Robots, pp. 59-64, Brescia, Italy.

Graf, R. \& Dillmann, R. (1999). Acceleration compensation using a Stewart platform on a mobile robot, Third European Workshop on Advanced Mobile Robots (Eurobot' 99), pp. 17 - 24, 6-8 Sept. 1999.

He, Y. \& Jinping , Z. (1997). Ocean Wave Spectrum Reconstruction from e s-1 Satellite Scatterometer Data, Proceedings of Geoscience and Remote Sensing, 1997 - IGARSS '97, IEEE, Remote Sensing - A Scientific Vision for Sustainable Development, Vol. 1 of, pp. 356-358.

Langlois, R. G. \& LaRosa M. (2003). T. A. R., Development, Validation, and Application of the Dynaface Helicopter/ship Dynamic Interface Simulation Software Package, Proceedings of the Summer Computer Simulation Conference, SCSC (Ed.), pp. 167-176.

Linn, D. \& Langlois, R. (2006). Development and Experimental Validation of a Shipboard Helicopter on-Deck Maneuvering Simulation. J. of Aircraft, Vol. 43, No. 4, pp. 895906.

Matusiak, J. (2002). Two-Stage Approach to Determination of Large Amplitude Motions of a Rigid Ship in Waves, Proceedings of the 15th Nordic Seminar in Computational Mechanics - NSCM15, pp. 1 - 10, Aalborg, Denmark.

Merlet, J. (2000). Parallel Robots, Kluwer Academic Publisher.

Nordforsk (1987). Assessment of a Ship Performance in a Seaway, The Nordic Cooperative Project, Sea Keeping Performance of Ships. Trondheim, Norway: Marintek.

Oh, S.; Pota, H.; Pathak, K. \& Agrawal, S. (2005). Autonomous Helicopter Landing on a Moving Platform Using a Tether, Proceedings of ICRA, pp. 3960-3965, Barcelona.

Oh, S.; Pathak, K.; Agrawal, S.; Pota, H. \& Garratt, M. (2006). Approaches for a TetherGuided Landing of an Autonomous Helicopter. IEEE Transactions on Robotics, Vol. 22, No. 3, june 2006, pp. 536-544.

Pajala, P. (2002). Wave Measurements, Maritime Institute of Finland, Sjkulla, Finland.

Pierrot, F.; Marquet, M.; Company, O. \& Gil, T. (2001). H4 Parallel Robot: Modeling, Design and Preliminary Experiments, Proceedings of ICRA, IEEE, pp. 3256-3261, Seoul.

Stewart D. (1996). A Platform with Six Degrees of Freedom, Proceedings of the Institution of Mechanical Engineers, Vol. 180, No. 15, pp. 371-386.

Thomas, U.; Maciuszek, I. \& Wahl, F. (2002). A Unified Notation for Serial, Parallel, and Hybrid Kinematic Structures, Proceedings of ICRA, Vol. 3, IEEE, pp. 2868-2873, Washington.

Tsai, L.-W. (1999). Robot Analysis: the Mechanics of Serial and Parallel Manipulators, John Wiley \& Sons, New York.

Vaillon, L.; Petitjean, B.; Frapard, B. \& Lebihan, D. (1999). Active Isolation in Space Truss Structures: from Concept to Implementation. J. of Smart Materials and Structures, Vol. 8, No. 6, pp. 781-790. 


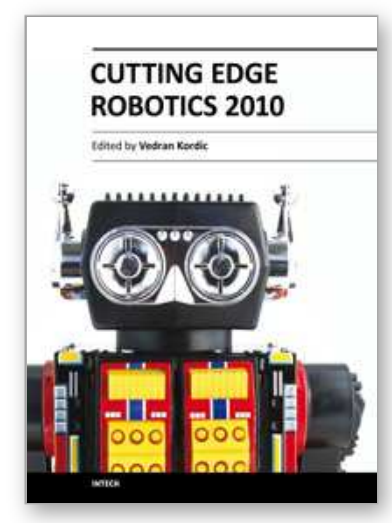

\author{
Cutting Edge Robotics 2010 \\ Edited by Vedran Kordic
}

ISBN 978-953-307-062-9

Hard cover, 440 pages

Publisher InTech

Published online 01, September, 2010

Published in print edition September, 2010

Robotics research, especially mobile robotics is a young field. Its roots include many engineering and scientific disciplines from mechanical, electrical and electronics engineering to computer, cognitive and social sciences. Each of this parent fields is exciting in its own way and has its share in different books. This book is a result of inspirations and contributions from many researchers worldwide. It presents a collection of a wide range of research results in robotics scientific community. We hope you will enjoy reading the book as much as we have enjoyed bringing it together for you.

\title{
How to reference
}

In order to correctly reference this scholarly work, feel free to copy and paste the following:

Alexandre Campos, Jacqueline Quintero, Roque Saltaren, Manuel Ferre and Rafael Aracil (2010). Robotic Strategies to Assist Pilots in Landing and Takeoff of Helicopters on Ships and Offshore, Cutting Edge Robotics 2010, Vedran Kordic (Ed.), ISBN: 978-953-307-062-9, InTech, Available from:

http://www.intechopen.com/books/cutting-edge-robotics-2010/robotic-strategies-to-assist-pilots-in-landing-andtakeoff-of-helicopters-on-ships-and-offshore

\section{INTECH}

open science | open minds

\section{InTech Europe}

University Campus STeP Ri Slavka Krautzeka 83/A 51000 Rijeka, Croatia Phone: +385 (51) 770447

Fax: +385 (51) 686166 www.intechopen.com

\section{InTech China}

Unit 405, Office Block, Hotel Equatorial Shanghai No.65, Yan An Road (West), Shanghai, 200040, China 中国上海市延安西路65号上海国际贵都大饭店办公楼405单元 Phone: +86-21-62489820

Fax: +86-21-62489821 
(C) 2010 The Author(s). Licensee IntechOpen. This chapter is distributed under the terms of the Creative Commons Attribution-NonCommercialShareAlike-3.0 License, which permits use, distribution and reproduction for non-commercial purposes, provided the original is properly cited and derivative works building on this content are distributed under the same license. 